\title{
Power System Analysis of 66/11 KV Distribution System of Samakhiyari, Kutch
}

\author{
${ }^{1}$ Raviraj Sindhav, ${ }^{2}$ Manmeet Joshi, ${ }^{3}$ Nayan Kumat, ${ }^{4}$ Sagar Modi \\ ${ }^{1234}$ B.Tech Student \\ ${ }^{1234}$ IITE, Indus University, Rancharda, Ahmedabad-382115
}

\begin{abstract}
This paper proposed Power System Analysis of 66/11 KV Distribution System of Samakhiyari, Kutch.

The system being planned is to be optimal with reference to construction cost, performance and operating efficiency. For this, better planning tools are required. In general, the main power grid tools are: load Flow Analysis, short circuit analysis or fault calculations, stability analysis etc. The purpose of an electric power system is to get and provide electricity to consumers with reliability and economy. The greatest threat to the system is that of the short circuit.The objective of this study is to simulate short circuit faults on different buses of a system network and to estimate the state of the system before and after a fault, which includes various bus voltages and current flow on various transmission lines.The following document contains necessary information about performing the two most important analysis on the power system.

1. Load flow analysis
\end{abstract}

2. Short circuit analysis

\section{INTRODUCTION}

Electrotherm (India) Ltd. has engineering metal melting trade since 1983. In Electrotherm from inception, R\&D has been Electrotherm's core competence with a typical concentrate on developing and adopting technologies to customise client wants and creating it a key driver in our Multi-Divisional growth story. Electrotherm is that the solely Indian company with indigenously developed world category technologies of world scale. Our team centered with a client 1 st perspective believes technology ought to be right-sized, with the process designed to reduce waste Associate in Nursing designated to boost product performance with an embedded attitude of customizing engineering and metallurgic solutions to customers that created Electrotherm grow into one amongst the market leaders within the metal melting industries in India and globally. Electrotherm nowadays could be a Multidivisional ISO 9001:2008 certified international Company holding a two,500,000 $\mathrm{kW}$ market share within the metal melting trade globally. Electrotherm could be a analysis driven company with Associate in Nursing appreciating plus in intellectual capital its primary supply of our multidivisional growth story. the corporate has developed robust processes with intrinsical learning and continuous enhancements in each job performed. This develops effective product lifecycle management and is that the foundation of our product innovations to confirm our customers attain their prime line growth. Engineering innovations for the worldwide metal melting trade has been potential thanks to our centered two,607 staff with a progressive producing facilities and R\&D centre manufactures a good spectrum of product for the metal melting trade and electrical vehicles \& are manufactured in four totally different divisions of the corporate. The client Focus of every division in manufacturing is in wheel with the R\&D to confirm our customers attain their objectives for prime line growth.

\section{OVERVIEW OF THE SYSTEM}

In electrotherm there are 2 units ISU and IPU i.e. Integrated Steel Unit and Integrated Pipe Unit. Both the units are connected with the substation which provide them power. Substation consists of BUS-1 and BUS- 2. Both the buses are connected by bus coupler. In case fault occurs in Bus 1 then supply can be provided with the help of Bus2 or vice versa. Electrotherm has its own Power plant which is known as Captive power plant, one is of $30 \mathrm{MW}$ and another one of 15 MW. Both the power plant produces power which is supplied to the substation by transmission line. Here $30 \mathrm{MW} \mathrm{CPP} \mathrm{is}$ connected to bus 1 and bus2 whereas $15 \mathrm{MW}$ is connected to bus 2.There is an alternative source of power which we received from GETCO Station. Here the switchyard is used to step down the $66 \mathrm{KV}$ to $11 \mathrm{KV}$ with the help of transformer 1 and transformer 2 of rating The transformer 1 is connected to bus 1 and transformer 2 is connected to bus2.In present time the $30 \mathrm{MW}$ CPP is in working condition and $15 \mathrm{MW}$ CPP is purposed. Power is generated from $30 \mathrm{MW}$ CPP and supplied to $11 \mathrm{KV}$ Bus line with the help of transmission line. Here in the system 2 loads is connected to the substation ISU and IPU.

ISU consist of four loads

1 Induction Furnace - 2F (SMS-2)

2 Induction Furnace-GH (SMS-2)

3 Induction Furnace- E (SMS-2)

4 Induction Furnace

IPU consist of four loads

Rolling mill

1 Space Iron plant

2 Yo bike division

3 SMS-1 and SMS-2

If fault occur in 30MW CPP there is an alternative source supply from 66KV switch yard from GETCO S/S. Here the $66 \mathrm{KV}$ line is further step down to $11 \mathrm{KV}$ line with the help of different panels and supplied to Bus 1 and Bus 2.And the supply continue from the substation to their respective unit.

Parts of Block Diagram

1.30MW Captive Power Plant

2.15MW Captive Power Plant

3. Switchyard $66 \mathrm{KV}$ 
4. Substation

5. Integrated Steel Unit

6. Integrated Pipe Unit

\section{LOAD FLOW ANALYSIS OF THE SYSTEM}

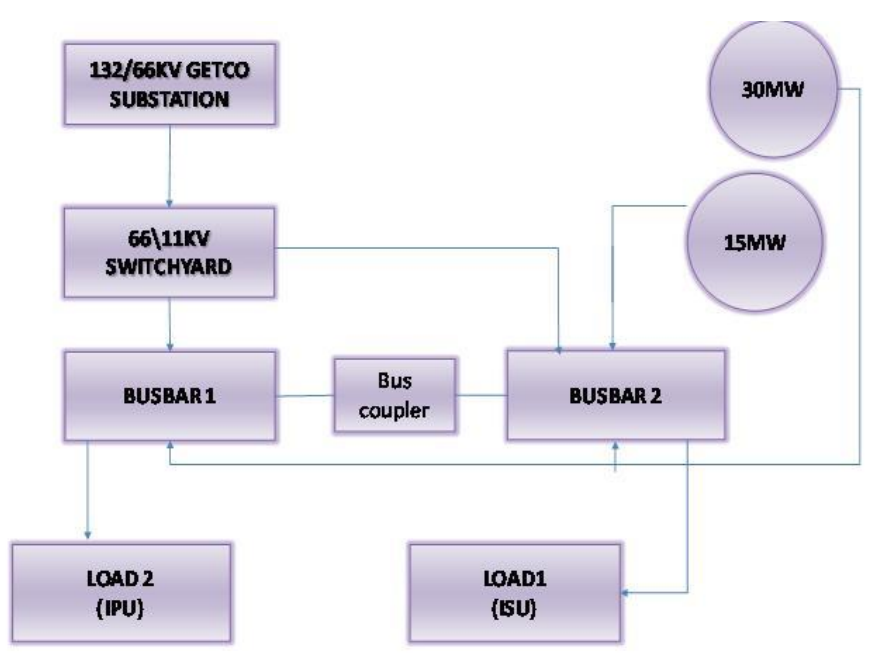

Fig.1 Block diagram of the system

\section{1) 30MW Captive Power Plant}

This Power Plant generates 30MW. There are two loads in Electrotherm which are Integrated Steel Unit and Integrated Pipe Unit. Both the load receives their respective power from $30 \mathrm{MW}$ CPP which are connected to the substation BUS 1 and BUS 2 .

\section{2) $15 M W$ Captive Power Plant}

This Power Plant generates 15MW. There is only one load connected to $15 \mathrm{MW}$ CPP and this CPP is connected with BUS2. BUS 2 transfers load to Integrated Steel Unit.

\section{3) Switch Yard $66 / 11 \mathrm{KV}$}

$66 \mathrm{KV}$ incoming line is coming from GETCO. There are two step down transformer of 30 MVA. Transformer step down the voltage to $11 \mathrm{KV}$. Here the $11 \mathrm{KV}$ line is supplied to the BUS 1 and BUS 2 .

\section{4) Substation}

$11 \mathrm{KV}$ supply is coming from $66 \mathrm{KV}$ Switch yard, which is connected to BUS1 and BUS2 which transfer the power to different loads i.e. Integrated Steel Unit and Integrated Pipe unit.

\section{5) Integrated Steel Unit}

In Integrated steel unit the supply is coming from the $11 \mathrm{KV}$ substation which transmits power to different load which are:

1. Induction Furnace $-2 \mathrm{~F}$ (SMS-2)

2. Induction Furnace-GH (SMS-2)

3. Induction Furnace- E (SMS-2)

4. Induction Furnace

All load capacity is $30 \mathrm{MW}$.

\section{6) Integrated Pipe Unit}

In Integrated pipe unit the supply is coming from the $11 \mathrm{KV}$ substation which transmits power to different load which are:
1. Rolling mill
2. Space Iron plant
3. Yo bike division
4. SMS-1 and SMS-2
All load capacity is $37.5 \mathrm{MW}$.

Load flow analysis is that the most significant and essential approach in investigating issues in facility operation and designing. The power flow analysis (also called the load flow Analysis) may be a vital and basic tool involving numerical analysis applied to an influence system. The results play a serious role within the day to day operation of any system for its control and economic schedule. The analysis is additionally utilized throughout power system operation procedures, designing growth and development of management strategies.

The purpose of any load flow analysis is to calculate precise steady-state voltages and voltage angles of all buses within the network, for fixed load, generator real power and voltage conditions. Once this info is thought, the important and reactive power flows into each line and electrical device, additionally as generator reactive power output are often analytically determined A power flow analysis for a system under actual or projected traditional operation conditions (base case) provide the results that represent a benchmark for comparison of changes within the network flows and voltages in abnormal conditions. The principal info obtained from power flow analysis, also known as the load flow study is that the magnitude and point in time of the voltage at each bus and real and reactive power flowing in every line. 


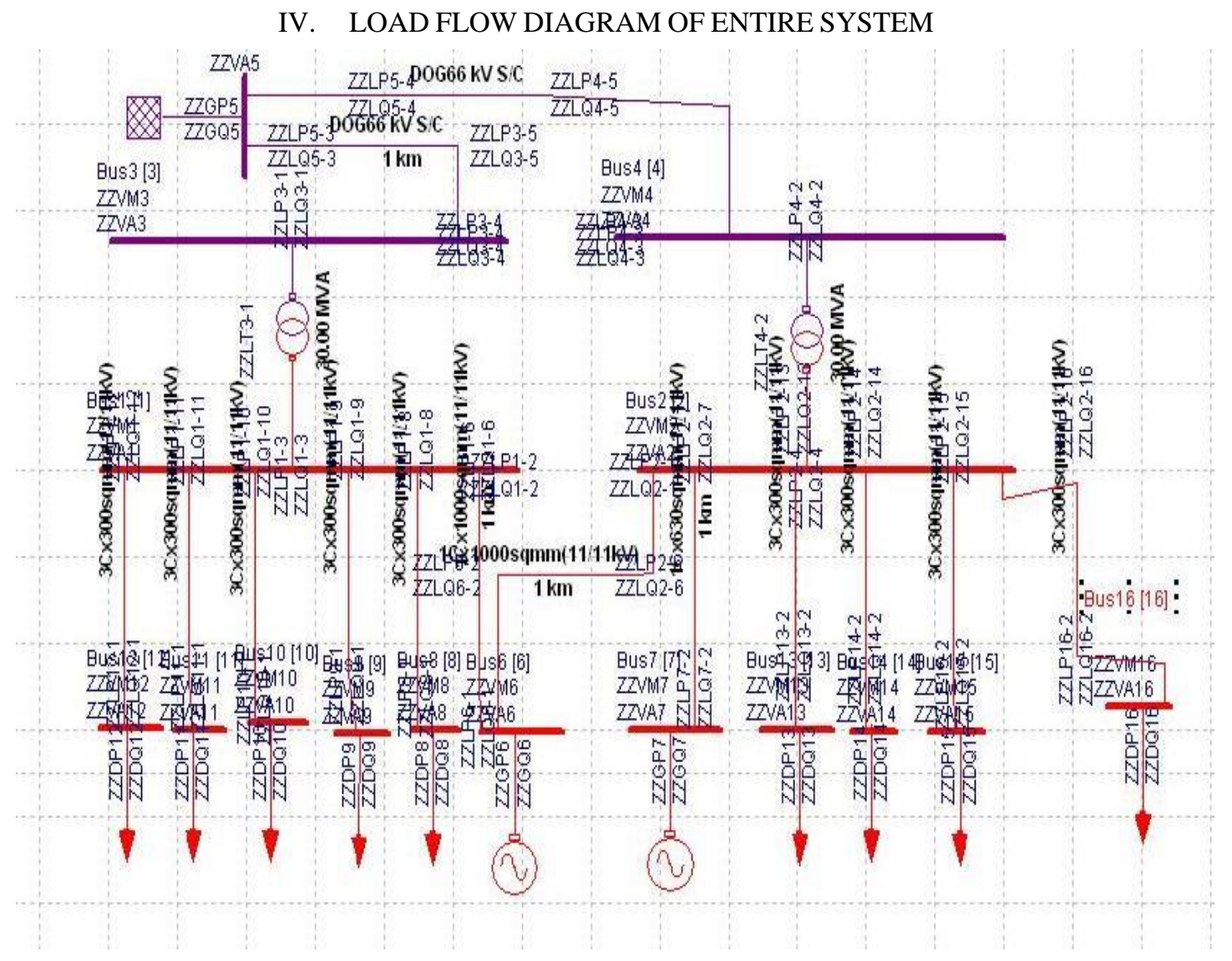

\section{LOAD FLOW RESULT OF ENTIRE SYSTEM}

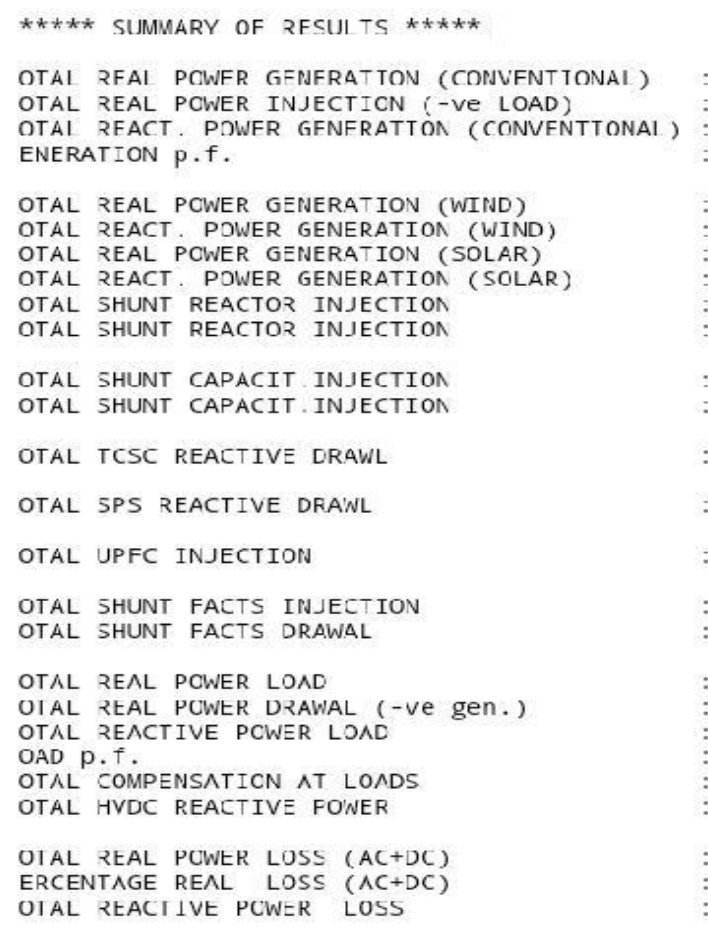

After analyze the MI-Power report of ET power system., We find out the $45 \mathrm{MW}$ real power generation,25.11 MVAR reactive power generation,2.83 MW total real

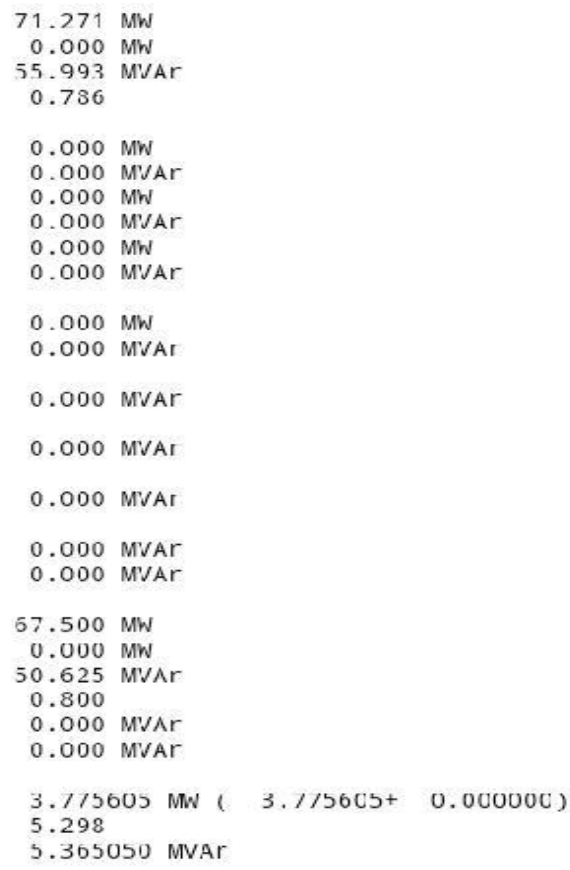

power loss, 2.61MVAr reactive power loss,30 MW total load, 22.5 MVAR total MVAR load. The Line which is connected with two bus no.(2) and bus no.(16). This line is 
overloaded because of the three generator connected with bus no.(2) Solution of this problem we can add more one transmission line connected between bus no.(2) and bus no.(16) which will reduce the overload of the transmission line otherwise we can change the load on another bus.

\section{SHORT CIRCUIT ANALYSIS}

Short circuit analysis basically consists of determining the steady state analysis of a linear network with balanced 3 part excitation. Such associate analysis provides currents and voltages during a power grid throughout the faulted condition. This information is required to work out the specified interrupting capability of the circuit breakers and to style correct relaying system. To gather enough data,

Different types of faults square measure simulated at completely different locations and also the study is repeated. ordinarily within the short circuit analysis, all the shunt parameters like masses, line charging ,admittances are neglected, Then the linear network that has got to be Solved includes of

- Transmission network

- Generator system and Fault. By properly combining the representations of these parts we will solve the short drawback

After studied about all fault analysis and their results we conclude that $3-\mathrm{Ph}$ line to ground fault is more savior than other faults and its short circuit current is $20.149 \mathrm{KA}$. Other side Single line to ground fault is less savior than to all other faults and its short circuit current is $16.679 \mathrm{KA}$.

\section{SUMMARY OF SHORT CIRCUIT ANALYSIS}

\begin{tabular}{|c|c|c|c|c|}
\hline FAULT & BUS & $\begin{array}{c}\text { RATED } \\
\text { VOLTAGE }\end{array}$ & MVA & CURRENT(KA) \\
\hline LLLG & BUS 15 & $11 \mathrm{KV}$ & 383.892 & 20.149 \\
\hline LLG & BUS 15 & $11 \mathrm{KV}$ & 383.892 & 20.009 \\
\hline LL & BUS 15 & $11 \mathrm{KV}$ & 383.892 & 17.641 \\
\hline LG & BUS 15 & $11 \mathrm{KV}$ & 383.892 & 16.679 \\
\hline
\end{tabular}

\section{CONCLUSION}

- After analyze the ISU unit of Power System. We find out the $45 \mathrm{MW}$ real power generations, 25.11 MVAR reactive power generations, $2.83 \mathrm{MW}$ total real power loss, 2.61MVAR reactive power loss, $30 \mathrm{MW}$ total loads, total reactive power load 22.5 MVAR.

- After analyze the entire Power System. We find out the 71.271 MW real power generations, 55.990 MVAR reactive power generations, 3.775 MW total real power loss, 5.365 MVAR reactive power loss, 67.5 MW total loads, total reactive power load 50.625 MVAR.

- The short circuit analysis of ET power system gives some short circuit current value as per fault type. Short circuit current of L-L-L-G fault is 20.149 KA, L-L-G fault is 20.009 KA, L-L fault is 17.641 KA and S-L-G fault is $16.679 \mathrm{KA}$.

\section{REFERENCES}

[1] MI-Power How to Solve, PRDC, Power Research and Development Consultants Private Limited

[2] Debniloy De, Shivanjali A. Mishra, Aditya Kar and Sheila Mahapatra "Short Circuit Analysis of a Power Grid using MIPower Software" Advance in Electronic and Electric Engineering. ISSN 2231-1297, Volume 4, Number 3 (2014), pp. 253-258

[3] Pranshu Shrivastava, Shweta Sahu Modi, Pooja Shrivastava "SHORT CIRCUIT ANALYSIS BY USING MI-POWER" International Journal of Engineering Research and Applications (IJERA) ISSN: 2248-9622 International Conference On Emerging Trends in Mechanical and Electrical Engineering (ICETMEE13th-14th March 2014)

[4] Ranjeet Kumar Gokulpure, Preeti Jain, "Review of Short Circuit Analysis in Power System" IJSRD - International Journal for Scientific Research \& Development| Vol. 3, Issue 05, 2015 | ISSN (online): 2321-0613

[5] 'Analysis of Faulted Power Systems' (Book) Paul M Anderson. IEEE Press Power Engineering Series, Year 1995.

[6] 'Power System Analysis - Short Circuit Load Flow And Harmonics' (Book) J. C.Das., Marcel Dekker Publication, Year 2002.

[7] 'Analysis of Faulted Power Systems' (Book) Paul M Anderson., IEEE Press Power Engineering Series, Year 1995.

[8] Hadi Saadat, Power System Analysis, McGraw-Hill

[9] William D. Stevenson, Elements of Power System Analysis, McGraw-Hill

[10] D. P. Kothari and I. J. Nagrath, Power System Engineering, Tata McGraw-Hill Education Private Limited, Second Editio 